This work may be downloaded only. It may not be copied or used for any purpose other than scholarship. If you wish to make copies or use it for a non-scholarly purpose, please contact AERA directly.

\title{
Against the Quantitative-Qualitative Incompatibility Thesis or Dogmas Die Hard
}

\author{
KENNETH R. HOWE
}

\begin{abstract}
Over approximately the last 20 years, the use of qualitative methods in educational research has evolved from being scoffed at to being viewed as useful for provisional exploration, to being accepted as a valuable alternative approach in its own right, to being embraced as capable of thoroughgoing integration with quantitative methods. Progress has been halting, and it is not surprising that certain thinkers are now balking at the latest stage of development. The chief worry is that the capitulation to "what works" ignores the incompatibility of the competing positivistic and interpretivist epistemological paradigms that purportedly undergird quantitative and qualitative methods, respectively. Appealing to a pragmatic philosophical perspective, this paper argues that no incompatibili. ty between quantitative and qualitative methods exists at either the level of practice or that of epistemology and that there are thus no good reasons for educational researchers to fear forging ahead with "what works."
\end{abstract}

f job descriptions and requests for proposals are accurate barometers, there seems to be little worry these days about combining quantitative and qualitative methods in educational research. Indeed, such a combination is not only encouraged, but often required. Certain thinkers, however (e.g., Guba, 1987; Smith 1983a, 1983b; Smith \& Heshusius, 1986), are wary of the growing rapprochement. These thinkers-advocates of what I call the "incompatibility thesis" believe that the compatibility between quantitative and qualitative methods is merely apparent and ultimately rests on the epistemologically suspect criterion of "what works." Accordingly, incompatibilists advise against "closing down" the debate about quantitative versus qualitative methods, on the grounds that current calls for rapprochement ignore hidden epistemological difficulties.

This paper will advance the view that the debate, at least as framed by incompatibilists, ought to be closed down and will advance an alternative view: the "compatibility thesis." The compatibility thesis supports the view, beginning to dominate practice, that combining quantitative and qualitative methods is a good thing and denies that such a wedding of methods is epistemologically incoherent. On the contrary, the compatibility thesis holds that there are important senses in which qua. .ative and qualitative methods are inseparable.

The argument will have two major threads. I will begin by briefly illustrating how, in practice, differences between quantitative and qualitative data, design, analysis, and interpretation can be accounted for largely in terms of differences in research interests and judgments about how best to pursue them. That differences can be accounted for in these ways should prompt suspicion about the need to posit different conceptions of reality and different epistemological "paradigms" to account for the use of different research methods and should lead one to wonder about whether the quantitative-qualitative debate is just an invention.

This initial suspicion will set the stage for the second, more elaborate, thread of argument. Incompatibilists maintain that problems arise not so much at the level of practice, but at the level of epistemological paradigms. In particular, they advance the following argument: Positivist and interpretivist paradigms underlie quantitative and qualitative methods, respectively; the two kinds of paradigms are incompatible; therefore, the two kinds of methods are incompatible. I will argue that a principle implicit in the incompatibilist's argument-that abstract paradigms should determine research methods in a one-way fashion-is untenable, and I will advance an alternative, pragmatic view: that paradigms must demonstrate their worth in terms of how they inform, and are informed by, research methods that are successfully employed. Given such a two-way relationship between methods and paradigms, paradigms are evaluated in terms of how well they square with the demands of research practice-and incompatibilism vanishes.

I will conclude my arguments by considering several criticisms that are commonly advanced against the pragmatic philosophical stance that will be used to defend compatibilism. Specifically, pragmatism rejects as irrelevant abstract epistemological considerations that cannot be squared with the actual practices employed in gaining empirical knowledge. ${ }^{1}$ As a consequence, pragmatism is often accused of holding truth hostage to "what works" and of therefore being committed to relativism and irrationalism. I will suggest that the threat of relativism and irrationalism purportedly posed by pragmatism is overdrawn, if not based on an outright misrepresentation of the pragmatic view, and that the alternative views of truth associated with the incompatibility thesis have serious problems of their own.

\section{The Incompatibility Thesis and Research Practice}

[In] any study, there are only bits and pieces that can be legitimated on "scientific" grounds. The bulk comes from common sense, from prior experience, from the logic inherent in the problem definition or the problem space. Take the review of the literature, the conceptual model, the key variables, the measures, and so forth, and you have perhaps $20 \%$ of what is really going into your study .... And if you look hard at that $20 \%$, if for example, you go back to the prior studies from which you derived many assumptions and perhaps some measures, you will find

KenNeth R. Howe is Assistant Professor, School of Education, 115 Education Building, University of Colorado at Boulder, Boulder, CO 80309-0249. He specializes in philosophy of education and professional ethics. 
that they, too, are $20 \%$ topsoil and $80 \%$ landfill. (Huberman, 1987, p. 12)

Huberman's reference to "landfill" makes a too-oftenneglected point about the necessity in any research study of employing a considerable amount of nonmechanical judgment. This section will take Huberman's observation as the point of departure and will briefly illustrate just how thoroughly and unavoidably nonmechanical judgment ("landfill') enters into the four basic components of research -data, design, analysis, and interpretation. The aim is to show that the quantitative-qualitative distinction is not pivotal within a larger scheme of background knowledge and practical research aims and that false impressions can result from the vague and ambiguous nature of the distinction.

\section{Data}

When applied to data, the quantitative-qualitative distinction is ambiguous between two senses: a measurement sense and an ontological sense. In the measurement sense, data are qualitative if they fit a categorical measurement scale; data are quantitative if they fit an ordinal, interval, or ratio scale. In the ontological sense, data are qualitative if they are "intentionalist" (i.e., incorporate values, beliefs, and intentions); data are quantitative if they are "nonintentionalist" (i.e., exclude values, beliefs, and intentions). ${ }^{2}$

Given these two senses of the quantitative-qualitative data distinction, four kinds of data are possible. Each kind is illustrated in the matrix depicted in Figure 1. Using the matrix to frame the question of the compatibility of various kinds of data, the burden for the incompatibility thesis, then, is to locate the source of incompatibility in either the rows, the columns, or the cells.

Incompatibilists would be hard pressed to show that the problem exists between the rows (i.e., with the measurement interpretations of the quantitative-qualitative data distinction). This would entail that researchers cannot mix variables that are on different measurement scales, which is absurd.

Perhaps the incompatibility is to be found between the columns (i.e., with the ontological interpretations). But this sort of incompatibility seems equally difficult to defend, for the implication would be that it is illicit to mix demographic variables like years of schooling and income with action variables like cooperativeness and critical thinking skills. This would condemn much, if not most, educational research as incoherent.

The remaining option for the incompatibilist is to bar one or more of the cells (i.e., to locate incompatibility in certain combinations of the measurement and ontological interpretations). The most suspect cell is II.

One view seems to be that quantifying over an ontologically qualitative concept objectifies it and divests it of its ontologically qualitative dimensions, that is, divests it of its value-laden and intentional dimensions. But by what sort of magic does this divestiture occur? Does changing from a pass-fail to an A-F grading scale, for instance, imply that some new, ontologically different, performance is being described and evaluated? If not, then why should the case be different when researchers move from speaking of things like critical thinking skills and cooperativeness in terms of present and absent, high and low, or good and bad to speaking of them in terms of $0-100$ ?
FIGURE 1

Kinds of Quantitative and Qualitative Data

$\frac{\text { Ontological }}{\text { Qualitative } \quad \text { Quantitative }}$

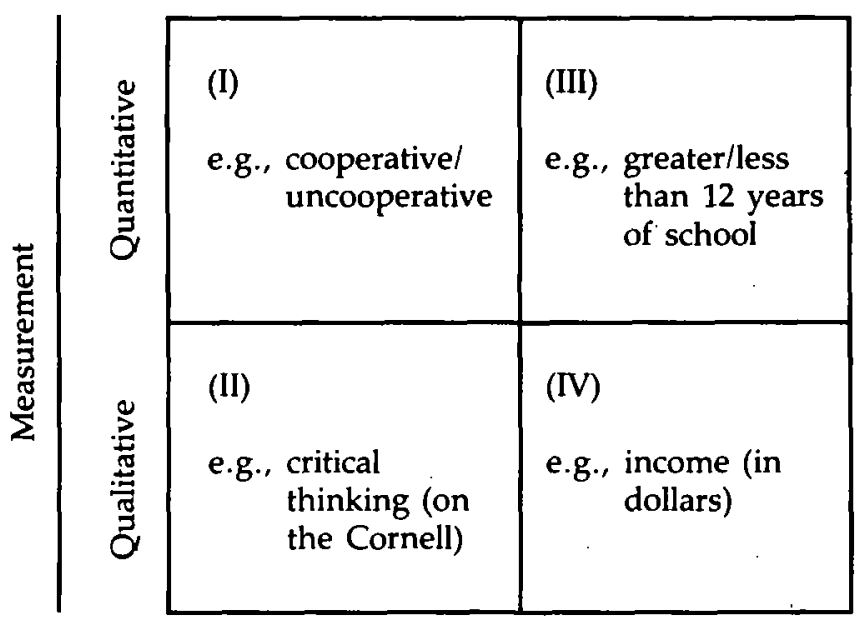

A second view seems to be that ontologically qualitative concepts are to be identified with the "insider's" perspective and that quantifying over them automatically shifts to the researchers' (or "scientific") perspective, thus divesting them of their ontologically qualitative dimensions in this way. But there are obvious counterexamples to this way of driving a wedge between quantitative and qualitative data. For instance, students give a description that is comprehensible from the insider's perspective but quantitative when they fill out instructional rating forms; researchers give a description that is incomprehensible from the insider's perspective but qualitative when they employ terms such as "cultural congruence.".

The arguments of the preceding several paragraphs indicate that quantification per se is not the source of incompatibility among data. It seems that incompatibility must therefore rest on the observation that certain kinds of qualitative data-for instance, texts, films, pictures, and speeches ${ }^{3}$-have no quantitative analogues. Granting that these kinds of data cannot be reduced to quantitative data (though there seems to be no good reason to bar counting and rating things, and even doing statistical tests on the resultant data), it is by no means obvious why this should be viewed as the mark of incompatibility. Why not simply adopt a pluralistic (compatibilist) attitude? Indeed, this is precisely the attitude expressed by reflective educational researchers when they go about the business of conceptualizing their research. Consider Jackson's remarks:

Classroom life, in my judgment, is too complex an affair to be viewed or talked about from any single perspective. Accordingly, as we try to grasp the meaning of what school is like for students and teachers we must not hesitate to use all the ways of knowing at our disposal. This means we must read, and look, and listen, and count things, and talk to people, and even muse introspective- 
ly over the memories of our own childhood. (1968, pp. vii-viii)

\section{Design and Analysis}

The quantitative-qualitative distinction is at once most accurately and most deceptively applied at the level of design and analysis. It is accurately applied because quantitative design and analysis involve inferences that are clearly more mechanistic (i.e., nonjudgmental or "objective") and more precise than qualitative design and analysis (indeed, many qualitative types would blanch at the suggestion they employ designs at all). It is deceptively applied because quantitative design and analysis, like qualitative design and analysis, also unavoidably make numerous assumptions that are not themselves mechanistically grounded.

Using "design" loosely, the qualitative researcher's design consists of some provisional questions to investigate, some data collection sites, and a schedule allocating time for data collection, analysis (typically ongoing), and writing up results. The quantitative researcher's design also has these elements, but the questions are more precisely and exhaustively stated and the schedule sharply distinguishes the data collection, analysis, and write-up phases of the research. Furthermore, the quantitative researcher will have clearly specified the research design (in a more strict sense) and the statistical analysis procedures to be employed.

The differences between these two researchers turns on, or at least ought to turn on, what each is attempting to investigate and what assumptions each is willing to make. That is, the qualitative researcher (rightly or wrongly) is willing to assume relatively little, to keep the investigation openended and sensitive to unanticipated features of the object of study. The qualitative researcher is also acutely sensitive to the particulars of the context, especially the descriptions and explanations of events supplied by actors involved. In contrast, the quantitative researcher (rightly or wrongly) is willing to assume much, e.g., that all confounding variables have been identified and that the variables of interest can be validly measured; quantitative researchers are also much less interested in actors'. points of view.

The chief differences between quantitative and qualitative designs and analysis can be accounted for in terms of the questions of interest and their place within a complex web of background knowledge. Because quantitative research circumscribes the variables of interest, measures them in prescribed ways, and specifies the relationships among them that are to be investigated, quantitative data analysis has a mechanistic, nonjudgmental component in the form of statistical inference. But, as Huberman (1987) notes, this component is small in the overall execution of a given research project, and it is far too easy to overestimate the degree to which quantitative studies, by virtue of employing precise measurement and statistics, are eminently "objective" and "scientific." One gets to the point of employing statistical tests only by first making numerous judgments about what counts as a valid measure of the variables of interest, what variables threaten to confound comparisons, and what statistical tests are appropriate. Accordingly, the results of a given statistical analysis are only as credible as their background assumptions and arguments, and these are not amenable to mechanistic demonstration. Furthermore, even highly quantitative studies require that the context be made intelligible by use of some sort of narrative ("qualitative") history of events (e.g., Campbell, 1979).

\section{Interpretation of Results}

The distinction between data analysis and interpretation of results is an admittedly artificial one, especially for qualitative research-but quantitative researchers by no means proceed in a lockstep fashion regarding interpretation, either. As studies enter their analysis and interpretation phases, quantitative researchers look for new confounds, new relationships, new ways of aggregating and coding data, etc., not envisioned in the original design. Except for being hemmed in by earlier decisions about what to measure and how to measure it, they look a lot like qualitative researchers: Both kinds of researchers construct arguments based on their evidence, ever wary of alternative interpretations of their data. Statistical analyses are merely instances of mechanical inferences in a much larger set of knowledge claims, assumptions, and instances of nonmechanical inferences.

The interpretation of research results is thus at most highly qualitative (nonmechanistic) or highly quantitative (mechanistic). That is, actual studies invariably mix kinds of interpretation, and whether a given study is dubbed "quantitative" or "qualitative" is a matter of emphasis. For instance, Coleman's work on equal opportunity fits the description "quantitative" despite his extended "qualitative" concern over just what his data mean with respect to the concept "equal educational opportunity" (Coleman, 1968). Conversely, Jackson's (1968) investigation of classroom life fits the description "qualitative" despite his modest use of "quantitative" methods.

In summary, the quantitative-qualitative distinction operates at three levels of research practice: data, design and analysis, and interpretation of results. At the level of data, the distinction between a "measurement" and an "ontological" sense is ambiguous. At the level of design and analysis, as well as interpretation, "qualitative" means "nonmechanistic" and "quantitative" means "mechanistic." At the second two levels, it is impossible to imagine a study that could avoid having "qualitative" elements. (This suggests that all research ultimately has a "qualitative grounding," Campbell, 1974.) With the exception of pure behavioristic studies (which never existed, according to Mackenzie, 1977), it is also impossible to imagine a study without "qualitative" elements at the level of data. Far from being incompatible, then, quantitative and qualitative methods are inextricably intertwined.

\section{Incompatibility Thesis and Epistemological Paradigms}

Are there deeper epistemological reasons, to which research practitioners are blind, for avoiding the combination of quantitative and qualitative methods?

Incompatibilists might very well grant the general thrust of the preceding section by responding that compatibility is possible with respect to "techniques and procedures" (Smith \& Heshusius, 1986) or the "methods level" (Guba, 1987). They would contend, however, that this is only a misleading surface compatibility and that at a deeper epistemological level-at "the logic of justification" or "paradigm" level-quantitative and qualitative methods are indeed incompatible because of the different conceptions of reality, truth, the relationship between the investigator and the object of investigation, and so forth, that each assumes. As Guba puts it, "The one [paradigm] precludes the other just as surely as belief in a round world precludes belief in a flat one" (p. 31). 
The incompatibility thesis (briefly described earlier) will now be more fully fleshed out. (Henceforth "paradigm" and "methods" will be used to mark the distinction between the levels of epistemology and research practice, respectively.)

One paradigm is positivism: the view that scientific knowledge is the paragon of rationality; that scientific knowledge must be free of metaphysics, that is, that it must be based on pure observation that is free of the interests, values, purposes, and psychological schemata of individuals; and that anything that deserves the name "knowledge," including social science, of course, must measure up to these standards. The other paradigm is interpretivism: the view that, at least as far as the social sciences are concerned, metaphysics (in the form of human intentions, beliefs, and so forth) cannot be eliminated; observation cannot be pure in the sense of altogether excluding interests, values, purposes, and psychological schemata; and that investigation must employ empathic understanding (as opposed to the aims of explanation, prediction, and control that characterize the positivistic viewpoint). The positivist and interpretivist paradigms are incompatible; the positivist paradigm supports quantitative methods, and the interpretivist paradigm supports qualitative methods. Therefore, quantitative and qualitative methods are, despite the appearance that research practice might give, incompatible.

There are at least two strategies that a compatibilist might employ against the incompatibilist argument. First, the compatibilist can argue that the two epistemological paradigms included in the incompatibilist's argument do not exhaust the possibilities. In particular, the pragmatic tradition, which includes James, Dewey, Wittgenstein, Quine, and Kuhn and, more recently, Rorty and Bernstein, has been left entirely out of the picture. ${ }^{4}$ This seems to be a serious omission, for pragmatists were largely responsible for bringing down positivism and would clearly reject the forced choice between the interpretivist and positivist paradigms. Second, the compatibilist can take the more direct approach (admittedly pragmatic in nature) of insisting that paradigms bring themselves into some reasonable state of equilibrium with methods (e.g., this is Nelson Goodman's move [1965] regarding the justification of inductive inference). That is, rather than divorcing paradigms from the conduct of research (but nonetheless having them dictate what is to count as legitimate knowledge), the compatibilist can insist on a mutual adjustment between the two such that practice is neither static and unreflective nor subject to the one-way dictates of a wholly abstract paradigm.

I have argued elsewhere (Howe, 1985) that the fall of positivism (and it has fallen) undermines the sort of forced choice between epistemological paradigms that undergirds the incompatibility thesis; that is, I have already made the first gambit against the incompatibility thesis (and Garrison, 1986, has recently offered more elaborate arguments that make the same point). Rather than continuing to beat this dead horse (whose ghost still stalks the pages of more than one educational journal), I will focus my attention on the second gambit.

Consider Kaplan's delightful story illustrating the "principle of the drunkard's search."

There is a story of a drunkard searching under a street lamp for his house key, which he had dropped some distance away. Asked why he didn't look where he had dropped it, he replied, "It's lighter here!" (1964, p. 11)
Consider now the way Smith and Heshusius (1986) write off the pragmatic (compatibilist) criterion of "what works."

In the end, what works is not a firm foundation to stand on. What works depends on the kind of work one wants inquiry to do, which in turn depends on the paradigm within which one is working. (p. 10)

The incompatibility thesis, like the drunkard's search, permits the "lights" to determine what is to be looked for and where. But why should paradigms determine the kind of work one may do with inquiry any more than the amount of illumination should determine where one may conduct a search? The possibility of modifying a paradigm (lighting apparatus) in response to the demands of research (the location of the key) seems to go unnoticed.

Eschewing this kind of "tyranny of method" (Bernstein, 1983) - of the epistemological over the practical, of the conceptual over the empirical-is the hallmark of pragmatic philosophy. Kaplan (1964) provides a particularly helpful account of how this general attitude applies to the relationship between research methods ("logic in use") and epistemological paradigms ("reconstructed logic"). In particular, he contends that the two levels are intimately connected and require mutual adjustment. The following brief caricature of the rise and fall of methodological behaviorism (my example, not Kaplan's) may serve as an illustration of how this adjustment process unfolds.

Around the turn of the century, psychology was in a state of disarray. The old introspectionist "logic in use" was developing internal problems and was failing to provide useful findings. A budding behaviorist logic in use provided competition for dominance by making claims to being scientific and promising to yield elaborate scientific theory. To solidify its position, behaviorism turned to the "reconstructed logic" provided by the positivists' analysis of natural science, and adopted that logic-with its demands for verifiability and its rejection of mental concepts and selfreports-as the methodological basis for their research. Thus, the positivistic reconstructed logic gained preeminence, and any research methodology that failed to measure up was dismissed as unscientific.

There were pragmatic philosophers (notably, Dewey) who rejected positivism's reconstruction of science consistently and from the start. To be consistent, however, pragmatists would have had to change their view if social science based on a positivistic reconstruction had "worked" at the level of a logic in use (though, to complicate matters, they would still have had the option open of arguing for a different set of aims and values). But the positivist-inspired behaviorist social science methodology has not worked at the level of logic in use-it has not lived up to its promise of providing elaborate theory and has outlived the usefulness it once had (e.g., Mackenzie, 1977). Consequently, there currently is no dominant reconstructed logic (paradigm), and many researchers have become enmeshed in logics in use (for educational researchers, quantitative and qualitative in particular), devising whatever methods seem appropriate for investigating important questions at hand. Thus, questions about logic in use-nitty-gritty questions about methods-are currently leading the way; and reconstructed logics, paradigms, need to be brought into line.

How to frame the problem that this state of affairs engenders is where compatibilists and incompatibilists part company. One of the central concerns behind incompati- 
bilism is legitimate: To the extent that preoccupation with methods prompts unreflectiveness and stifles progress, educational researchers ought to be pressed to take a look at deeper epistemological issues. Unfortunately, all that incompatibilism seems to have to offer is a forced choice between two exclusive paradigms and the spin-off'of a fragmented research community-with one group championing the view that their method is the only truly "scientific" one (a view that may be associated with certain hard-headed positivist types), and the other group embracing "multiple realities" (Phillips, 1987) so that researchers are free to speak their own languages, investigate their own questions, and come up with their own standards of truth (a view that may be associated with certain soft-headed interpretivist types). Neither dogmatic adherence to the positivistic pipe dream nor chaotic methodological relativism (let alone the two, side by side) promise to advance research.

The way out of this dilemma is to give up the notion that social research must be either just like physical science or fundamentally different from it. The incompatibility thesis ignores this possibility because, to borrow again from Kaplan (1964), it confuses "two things to understand" (intentionalist and nonintentionalist) with "two kinds of understanding" (scientific and interpretive). The compatibilist view admits that social research needs to use a vocabulary appropriate for describing social events, which means using intentionalist ("ontologically qualitative") concepts. Compatibilism admits as well that physics has no need for such concepts. Unlike the subjects of social research, the objects of physical research cannot question the way researchers choose to describe them, provide their own accounts of why events happened as they did, or alter their behavior in response to researchers' claims. Compatibilism thereby grants something to the interpretivist paradigm regarding the special nature' of social research.

On the other hand, compatibilism denies that it is incoherent to quantify over intentionalist concepts, to employ nonintentionalist concepts, or to sometimes ignore or dismiss actors' descriptions and accounts of events. In addition, insofar as the "new philosophy of science" entails that even physics has its interpretive (nonmechanical and hermeneutical) elements (e.g., Giddens, 1976; Phillips, 1987), compatibilism also denies that social research must employ any unique kind of understanding. Compatibilism thereby grants something to the positivist paradigm regarding the-uniformity of scientific reasoning. By granting something to both paradigms, compatibilism thus steers a middle course that avoids running aground on either the positivist or interpretivist methodological islands.

Of course, moving beyond a forced choice between exclusive epistemological paradigms does not end the conversation about social research methodology, but it does change its focus-from whether combining positivistic and interpretivist elements is legitimate to how this combination is to be accomplished.

Giddens, in his suggestively titled New Rules of Sociological Method (1976), contends that social research must work back and forth between the technical, scientific vocabulary of social science and the wordaday, natural vocabulary of social conduct through a process he dubs the "double hermeneutic." In a similar vein, Geertz (1979) argues that an understanding of human behavior requires a "continuous dialectical tacking between the most local of local detail and the most global of global structure" (p. 239). According to Geertz, social researchers must employ both "experiencenear" concepts (thereby capturing an important element of the interpretivist paradigm) and "experience-distant" concepts (thereby capturing an important element of the positivist paradigm) to arrive at an adequate understanding:

Confinement to experience-near concepts leaves an ethnographer awash in immediacies as well as entangled in vernacular. Confinement to experience-distant ones leaves him stranded in abstractions and smothered in jargon. The real question. . . is what kinds of roles the two kinds of concepts play in anthropological analysis. To be more exact: How, in each case, should they be deployed so as to produce an interpretation of the way people live which is neither imprisoned within their mental horizons, an ethnography of witchcraft as written by a witch, nor systematically deaf to the distinctive tonalities of witchcraft as written by a geometer? (1979, p. 227)

Notions like Geertz's "dialectical tacking" and Giddens's "double hermeneutic" suggest the outlines of the kind of compatibilist viewpoint that may supplant the incompatibilist's forced choice (and these authors have worked out their methodological views in much greater detail than presented here). A central feature of their view is that it not only permits combining paradigms, it requires such a combination.

\section{Some Observations About Pragmatism and Truth}

The defense of compatibilism provided in this paper has rested heavily on an appeal to pragmatic philosophy and is thus likely to be dismissed on the grounds that the pragmatic criterion of "what works" is fatally flawed. The argument against the criterion is a simple one that goes like this: What worked for Newton is not what worked for Einstein, and it is absurd to say that the universe switched from being Newtonian to being Einsteinian early in the 20th century. If the universe did change its nature early in the 20th century in response to "what works" (rather than having its true nature discovered), science is irrational and relativistic. Thus, the "what works" criterion is untenable. Q.E.D.

This attempt to dispense with pragmatism is far too facile, chiefly because pragmatists aren't about to let the distinction between "what works" and the "true nature" of things get off the ground-a point that is apparently often unappreciated (e.g., Phillips, 1983; Smith \& Heshusius, 1986). ${ }^{.}$The pragmatic stance can at least be clarified, if not made more appealing, by examining the attitudes toward truth, relativism, and irrationalism that pragmatists indeed hold.

\section{Truth Is "What Works"}

Pragmatists who are on their toes resist the temptation to provide a theory of truth by filling in the blank in " $X$ is true if and only if " with " $X$ works," " $X$ is a warranted assertion," "X helps us cope," and so on (Rorty, 1982b). If they give in to this temptation, absurdity quickly results. Was the earth flat when this belief "worked"? For pragmatists, "truth" is a normative concept, like "good," and "truth is what works" is best seen not as a theory or definition, but as the pragmatists' attempt to say something interesting about the nature of truth an to suggest, in particular, that knowledge claims cannot be totally abstracted 
from contingent beliefs, interests, and projects. It is illicit to criticize the pragmatic "theory" of truth when pragmatists refuse to offer one. After all, much of pragmatic philosophy (e.g., Davidson, 1973; Rorty, 1982a; Wittgenstein, 1958) is deconstructive-an attempt to get philosophers to stop taking concepts such as "truth," "reality," and "conceptual scheme," turning them into superconcepts such as "Truth," "Reality," and "Conceptual Scheme," and generating insoluble pseudoproblems in the process.

\section{Pragmatism and Truth, Relativism, and Irrationalism}

The alternative to the pragmatic conception is the forced choice between truth as correspondence and truth as coherence. Correspondence theories identify truth with a relationship between language and reality; coherence theories identify truth with internal consistency among claims within a language. The problem with correspondence theories is ever knowing when the relationship between a language and reality holds. Because there is no way to prevent knowledge of the world from being in some sense "filtered" by belief systems, there is no way to know when knowledge claims are contaminated. The problems with coherence theories is that they ignore the problem of the relationship between language and reality altogether. Because a theory can obviously be consistent but false (few theories have been abandoned because they were internally inconsistent), and because there can obviously be more than one internally consistent theory, knowledge becomes relative to belief systems (or Conceptual Schemes) and therefore irrational.

Pragmatists are often attributed with embracing a coherence theory, but this misrepresents their position. For pragmatists do not take sides on the problem of coherence versus correspondence theories of truth; instead, they reject the problem altogether. Davidson (1973) and Rorty (1982a), for instance, argue that for the problem to get off the ground, some Reality, some "given," totally independent of beliefs and knowledge claims, must exist; otherwise, there is no dilemma of either matching up language and reality or remaining trapped, so to speak, within one's own belief system. They deny that any sense can be made of a "given" that, by its very nature, can never be known, and therefore they deny that a dilemma exists about the nature of truth.

Pragmatists are also often attributed with embracing relativism and irrationalism. If embracing relativism means embracing the view that no fail-safe, eternal "neutral matrix" exists for determining what theories are correct, pragmatists are relativists; if embracing relativism means embracing the view that no grounds exist for rationally evaluating theories, they are not. Pragmatists supplant coherence and correspondence with criteria such as accuracy, scope, simplicity, consistency, and comprehensiveness (e.g., Kuhn, 1977; Quine, 1970) and contend that basing theory choice on these criteria entails not that science is irrational, but that scientific rationality simply does not fit the positivistic (i.e., mechanistic) account (Kuhn).

The pragmatic suggestion regarding research methodology is thus for researchers to forge ahead with "what works." Given a charitable interpretation of what this suggestion means, and in light of the alternatives of both an interminable debate about correspondence and coherence theories of truth and an invidious incompatibility thesis, the pragmatic alternative cannot be so easily dismissed. ${ }^{6}$

\section{Conclusion}

The quantitative-qualitative distinction is applied at various levels: data, design and analysis, interpretation of results, and epistemological paradigms. At the level of data, the "ontological" distinction cuts across the "measurement" distinction. In practice, educational researchers mix quantitative and qualitative data, in both senses. In this way, socalled quantitative studies are pregnant with (ontologically) qualitative concepts.

At the levels of design, analysis, and interpretation of results, quantitative and qualitative researchers differ chiefly in the assumptions they are willing to make and how much attention they pay to "experience-near" data. There are no doubt many important differences in the kinds of methods employed, but these differences are often blown out of proportion, to the point of positing two fundamentally divergent paradigms, two views of reality, and other such polar extremes. The existence of two sets of methods entails at most that having more than one set of tools is useful. In particular, the fact that quantitative analysis involves precise statistical inferences is analogous to the fact that one might be able to employ a deductive syllogism or two in a complex political argument. In both the research and political cases, numerous assumptions, hunches, conjectures, and value judgments loom large in designing and conducting research, and in evaluating proffered conclusions.

At the level of epistemological paradigms, philosophy of science has moved on, into a "new" or "postpositivistic" era. Questions about methodology remain, but they ought not be framed in way that installs abstract epistemology as a tyrant or that presupposes the moribund positivistinterpretivist split. The fact that quantitative and qualitative methods indeed might be historical outgrowths of incompatible positivist and interpretivist epistemologies no more commits present-day researchers to endorsing one or the other of these epistemologies than the fact that astronomy is an outgrowth of astrology commits present-day astronomers to squaring their predictions with their horoscopes.

To conclude in the spirit of pragmatism, the sort of methodological compatibilism I have been promoting has several practical consequences.

Certain educational researchers will be made insecure by compatibilism insofar as it blurs methodological lines. That is, compatibilism does not permit researchers to isolate themselves within methodological paradigms that are impervious to the challenges and contributions of alternative perspectives. Although few researchers can be expected to master and pursue both quantitative and qualitative methods, they need at least a rudimentary understanding of what alternative approaches can provide and, accordingly, they should bring a collaborative (rather than paradigmclique) attitude to research.

For their part, certain philosophers will be made insecure by compatibilism insofar as it blurs the lines between philosophical theory (epistemology) and research practice (methods). But in the end, a philosophical perspective is valuable just to the extent that it helps shape practice, and helping to shape a practice requires careful attention to just what the practice is.

The growing tendency of educational researchers to resist the tyranny of methodological dogma is a good thing. It is high time to close down the quantitative versus qualitative conversation. 


\section{Notes}

I thank Linda Vavrus and the reviewers of $E R$ for their many useful comments.

'It will be useful to distinguish the "compatibility thesis" from a view with which it might be confused: the "autonomy thesis." The autonomy thesis (e.g., Reichardt \& Cook, 1979, and perhaps Firestone, 1987 ) is the view that the practice of research floats free of epistemological considerations. That is, researchers can safely ignore epistemological considerations because they don't provide any guidance regarding practice-in particular, epistemological considerations neither rule in nor rule out quantitative methods, qualitative methods, or some combination. At bottom, then, the autonomy thesis presupposes a certain view of philosophy: the "queen science," as Rorty (1979) calls it, passing judgment on the legitimacy of knowledge claims of scientists from some privileged vantage point. Because the queen science view entails that philosophy can be abstracted from actual practice, it follows that philosophical theory has little guidance to provide regarding practice. Hence, the quantitative-qualitative controversy dissolves, à la Reichardt and Cook, into a merely practical one about "what works."

In one sense, the autonomy thesis is correct: Reichardt and Cook show (contra Smith and Heshusius) that the distinct epistemologies ("paradigms") that purportedly underlie quantitative and qualitative methods do not indeed logically entail different methods at the level of research practice. (In defense of Smith and Heshusius, there is at least a very close relationship between paradigms and research methods, even if it falls short of the strict standard of logical entailment-Phillips's [1983] positivist ethnographer would be a weird duck indeed.) Rather than dismissing the relevance of epistemology, however, which is what Reichardt and Cook in effect do, the correct move is to dismiss epistemology that is irrelevant. That is, Reichardt and Cook simply accept the purported split between paradigms (which entails multiple realities and other such nonsense) without questioning the paradigms themselves (little wonder that paradigms bear no logical connection to practice). But eliminating such nonsense should be the focus of analysis. Thus, the autonomy thesis may be dismissed both because it fails to locate the source of the problem and because it is far too tolerant of epistemological incoherence.

il have invented the ontologically qualitative/ontologically quantitative distinction to facilitate communication, insofar as it is cast in terms of the familiar qualitative/quantitative language, common in educational journals. In my estimation, the philosophical distinction between intentionalist and nonintentionalist concepts is more accurate and precise.

II owe these examples (though not necessarily my use of them) to an anonymous $E R$ reviewer.

"Interestingly, Smith and Heshusius cite Rorty and Bernstein, apparently in support of the incompatibility thesis. This is more than a little puzzling, for Rorty and Bernstein have their feet squarely in compatibilism (pragmatism). Rorty (1982a) wants to "stop asking" and Bernstein (1983) wants to "move beyond" the very questionsabout realism versus idealism and objectivism versus relativism-that Smith and Heshusius argue are at the bottom of the incompatibility thesis.

${ }^{5} \mathrm{My}$ use of Phillips in this context should not be taken to mean that I would classify him as an incompatibilist. My reading of him (1983, 1987) suggests that our similarities are much greater than our differences. In particular, he would probably endorse some form of compatibilism, but would ground it in the views of Karl Popper rather than in pragmatism.

"I make no pretense of having "defeated" realism and/or a correspondence theory of truth; my primary aim was to give pragmatism a fairer hearing than it typically receives. It is interesting, however, to examine just what would constitute success for philosophers working on the problem, which pragmatists reject, of specifying the language/reality relationship. Consider the British philosopher Michael Dummet's claim:

For the realists, we have assigned a meaning to... statements in such a way that we know, for each statement, what has to be the case for it to be true.... The condition for the truth of a statement is not, in general, a condition we are capable of recognizing as obtaining whenever it obtains, or even one for which we have an effective procedure for determining whether it obtains or not. We have therefore succeeded in ascribing to our statements a meaning of such a kind that their trulth or falsity is, in general, independent of whether we know, or have any means of knowing what trulh value they have. (in Rorty, 1982b; p. xxvii, emphasis added)
This passage brings to mind a remark of Wittgenstein's: "A wheel that can be turned though nothing else moves with it, is not part of the mechanism" (1958, sec. 271). It might give certain philosophers some comfort to be able to show that a reality exists which we can know nothing about, but it is difficult, to say the least, to see how this has anything whatsoever to do with the problem of working out methods of obtaining knowledge.

\section{References}

Bernstein, R. (1983). Beyond objectivism and relativism. Philadelphia: University of Pennsylvania Press.

Campbell, D. (1974). Quantitative knowing in action research. Kurt Lewin Award Address, Society for the Psychological Study of Social Issues, presented at the annual meeting of the American Psychological Association, New Orleans.

Campbell, D. (1979). Degrees of freedom and the case study. In T. Cook \& C. Reichardt (Eds.), Qualitative and quantitative methods in evaluation research (pp. 49-67). Beverly Hills, CA: Sage.

Coleman, J. (1968). The concept of equal educational opportunity. Harvard Educational Review, 38(1), 7-22.

Davidson, D. (1973). On the very idea of a conceptual scheme. Proceedings of the American Philosophical Association, 68, 5-20.

Firestone, W. (1987). Meaning in method: The rhetoric of quantitative and qualitative research. Educational Researcher, 16(7), 16-21.

Garrison, J. (1986). Some principles of postpositivistic philosophy of science. Educational Researcher, 15(9), 12-18

Geertz, C. (1979). From the native's point of view: On the nature of anthropological understanding. In P. Rabinow \& W. Sullivan (Eds.), Interpretive social science (pp. 225-242). Berkeley: University of California Press.

Giddens, A. (1976). New rules of sociological method. New York: Basic Books.

Goodman, N. (1965). Fact, fiction, and forecast. Indianapolis, IN: BobbsMerrill.

Guba, E. (1987). What have we learned about naturalistic evaluation? Evaluation Practice, 8(1), 23-43.

Howe, K. R. (1985). Two dogmas of educational research. Educational Researcher, 14(8), 10-18.

Huberman, M. (1987). How well does educational research really travel? Educational Researcher, 16(1), 5-13.

Jackson, P. (1968). Life in classrooms. New York: Holt, Rinehart and Winston.

Kaplan, A. (1964). The conduct of inquiry. San Francisco: Chandler.

Kuhn, T. (1977). The essential tension. Chicago: University of Chicago Press.

Mackenzie, B. (1977). Behaviorism and the limits of scientific method. Atlantic Highlands, NJ: Humanities Press.

Phillips, D. C. (1983). Postpositivistic educational thought. Educational Researcher, 12(5), 4-12.

Phillips, D. C. (1987). Philosophy, science, and social inquiry. New York: Pergamon.

Quine, W. V. O. (1970). The basis of conceptual schemes. In C. Landesman (Ed.), The foundations of knowledge (pp. 160-172). Englewood Cliffs, NJ: Prentice-Hall.

Reichardt, C., \& Cook, T. (1979). Beyond qualitative versus quantitative methods. In T. Cook \& C. Reichardt (Eds.), Qualitative and quantitative methods in evaluation research (pp. 7-32). Beverly Hills, CA: Sage.

Rorty, R. (1979). Philosophy and the mirror of nature. Princeton, N]: Princeton University Press.

Rorty, R. (1982a). Pràgmatism, relativism and irrationalism. In R. Rorty, Consequences of pragmatism (pp. 160-175). Minneapolis: University of Minnesota Press.

Rorty, R. (1982b). Pragmatism and philosophy. In R. Rorty, Consequences of pragmatism (pp. viii-xlviii). Minneapolis: University of Minnesota Press.

Smith, J. K. (1983a). Quantitative versus qualitative research: An attempt to clarify the issue. Educational Researcher, 12(3), 6-13.

Smith, J. K. (1983b). Quantitative versus interpretive: The problem of conducting social inquiry. In E. House (Ed.), Philosophy of evaluation (pp. 27-52). San Francisco: Jossey-Bass.

Smith, J. K., \& Heshusius, L. (1986). Closing down the conversation: The end of the quantitative-qualitative debate among educational researchers. Educational Researcher, 15(1), 4-12.

Wittgenstein, L. (1958). The philosophical investigations (2nd ed.). New York: Macmillan. 